\title{
Ensaio sobre os efeitos da minirreforma tributária sobre o emprego industrial paranense
}

Carlos Eduardo Fröhlich ${ }^{*}$

Luiz Alberto Esteves ${ }^{* *}$

RESUMO - Em dezembro de 2008, tramitava na Assembléia Legislativa do Estado do Paraná um projeto de lei que propunha redução na alíquota do Imposto sobre Circulação de Mercadorias e Serviços (ICMS) de cerca de 95 mil itens de consumo, ao mesmo tempo em que sugeria o aumento do percentual do imposto a incidir sobre a gasolina, energia elétrica, telefonia, bebidas alcoólicas e fumo. Este artigo apresenta os primeiros passos em direção à determinação das consequencias que a aprovação do projeto poderá apresentar ao emprego industrial formal paranense.

Palavras-chave: ICMS. Minirreforma tributária. Emprego industrial paranaense.

\section{INTRODUÇÃO}

Em novembro de 2008, o Governo do Estado do Paraná enviou à Assembléia Legislativa um anteprojeto de lei que busca reduzir, em pelo menos seis pontos percentuais, a alíquota do Imposto sobre Circulação de Mercadorias e Serviços de cerca de 95 mil itens, entre alimentos, medicamentos, produtos de higiene e eletrodomésticos. A perda na arrecadação, estimada pela Secretaria de Estado da Fazenda em R \$ 409,6 milhões, deve ser compensada por $\mathrm{R} \$ 412$ milhões provenientes do aumento da alíquota do ICMS da gasolina, energia elétrica, telefonia, bebidas alcoólicas e fumo.

Se aprovado pelo Legislativo, o texto, que recebeu a denominação Projeto de Lei n. ${ }^{\circ}$ 402/08 ao começar a ser discutido pela Assembléia Legislativa em 10 de dezembro, trará implicações adversas à produção, e consequentemente ao emprego, nas atividades cujos produtos passarem por aumento da alíquota do ICMS, ao mesmo tempo em que favorecerá a criação de novos postos de trabalho em atividades em que o imposto for afetado de maneira oposta. Tais implicações deverão apresentar-se tanto ao emprego industrial quanto às atividades de comercialização desses produtos.

A idéia de que um aumento na alíquota de um determinado produto trará implicações negativas para sua produção e consumo é baseada no que a teoria econômica

\footnotetext{
* Bacharel em Matemática e graduando em Ciências Econômicas pela Universidade Federal do Paraná. Atualmente é membro da equipe técnica do Boletim Economia \& Tecnologia. Endereço eletrônico: carlos.e.frohlich@gmail.com.

** Doutorando em Economia pela Università degli Studi di Siena. Atualmente é Professor Assistente do Departamento de Economia da Universidade Federal do Paraná. Endereço eletrônico: esteves@ufpr.br.
} 
denomina de peso morto dos impostos, i.e., a perda de bem-estar de produtores e consumidores gerada pelo imposto (VARIAN, 2006, p. 267). O mesmo argumento sugere que uma redução tarifária implicará em aumento na produção e consumo do bem beneficiado por tal redução. No entanto, a extensão de tais efeitos depende das elasticidades da oferta e demanda de cada bem afetado pela mudança tarifária.

Uma análise rigorosa dos efeitos da minirreforma tributária sobre produtores e consumidores demandaria a estimação das curvas de oferta e demanda de cada um dos produtos sujeitos a mudança tributária. Seria o caso de uma análise de equilíbrio parcial.

No que diz respeito à produção e ao emprego, as perguntas centrais são: qual é o tamanho do emprego industrial formal paranaense que potencialmente receberá influências, positivas ou negativas, da possível aceitação do projeto pela Assembléia Legislativa? Qual é a qualificação da mão-de-obra empregada nas atividades com perspectiva de alteração do ICMS, e a remuneração média desses trabalhadores?

No que se refere à possível positividade das influências da minirreforma tributária sobre o emprego, a resposta para a primeira pergunta demanda um trabalho muito mais extenso do que apenas inferir as elasticidades de oferta e demanda de cada bem, pois a produção e o emprego são determinados por uma cadeia de produção, onde todos os setores são, em alguma extensão, interligados. A resposta para a pergunta acima demandaria uma análise de equilíbrio geral.

Não será o objetivo dessa nota efetuar análises de equilíbrio (parcial ou geral), pois tal pesquisa extrapola uma análise de conjuntura. Mais restrito, este trabalho busca expor um retrato, ainda que difuso, do emprego industrial paranaense que poderá ser influenciado pela proposta do governo - sem, no entanto, lançar mão de análises do tipo custo-benefício para atestar se o efeito líquido da minirreforma tributária é positivo ou negativo, uma vez que essa análise exigiria cálculos da elasticidade-preço da demanda e da oferta de pelo menos 95 mil itens, esforço que nos distanciaria do escopo deste artigo.

\section{METODOLOGIA E FONTE DOS DADOS}

O texto enviado pelo Governo do Estado do Paraná ao Poder Legislativo previa a redução da alíquota do ICMS de 95 mil itens. O percentual do preço do produto referente ao imposto seria reduzido de 18\% para 12\% nos artigos classificados como alimentos, calçados, vestuário, artigos de cama, mesa e banho, têxteis, medicamentos, vacinas, produtos farmacêuticos e de higiene pessoal, madeira, fogões, microondas, máquinas de lavar roupa, secadoras de roupa, refrigeradores, congeladores, liquidificadores, batedeiras e sacolas 
ecológicas. A alíquota incidente sobre outros itens, como xampus e desodorantes, passaria por redução de $25 \%$ para 12\%. Em contrapartida, o ICMS aumentaria de $27 \%$ para $29 \%$ na energia elétrica, telecomunicações, cigarros e bebidas, e de $26 \%$ para $28 \%$ na gasolina.

Com essas listas de produtos com expectativa de alta ou baixa do ICMS, obtemos as Divisões da Classificação Nacional de Atividades Econômicas (CNAE) que contêm produtos que deverão passar por mudança na alíquota do imposto. Da lista dessas Divisões, então usada em conjunto com a Relação Anual de Informações Sociais (RAIS), do Ministério do Trabalho e Emprego, obtemos as seguintes informações acerca das Divisões da CNAE que contêm mercadorias e serviços que deverão passar por alteração na alíquota do ICMS: o número de empregados formais de cada uma das Divisões; o tamanho médio dos estabelecimentos que os empregam, em número de trabalhadores; a porcentagem de trabalhadores com curso superior completo; e a remuneração média desses trabalhadores. Os dados usados nesta pesquisa correspondem ao triênio 2005-2007.

Esses dados nos dão uma perspectiva, todavia inexata, do emprego que deverá sentir os efeitos do Projeto de Lei n. ${ }^{\circ}$ 402/08, caso este seja aceito pela Assembléia Legislativa nos moldes aqui explanados.

\section{RESULTADOS E ANÁLISE}

As Divisões da CNAE que correspondem à atividade industrial e contêm produtos cuja alíquota do ICMS deverá ser elevada são: 06 Extração de Petróleo e Gás Natural; 11 Fabricação de Bebidas; 12 Fabricação de Produtos do Fumo; 35 Eletricidade, Gás e Outras Utilidades; e 61 Telecomunicações. Consideradas essas categorias, a base de dados da RAIS, entretanto, dispunha de informações somente sobre as Divisões 11, 35 e 61, nos dias em que os levantamentos que embasam este artigo foram feitos. Nossa perspectiva sobre o emprego nas atividades cujos produtos devem passar por alta do imposto são feitas com base nas estatísticas sintetizadas na Tabela 1 .

Do outro lado, deverão passar por diminuição da alíquota do ICMS mercadorias e serviços das Divisões CNAE 01 Agricultura, Pecuária e Serviços Relacionados; 02 Produção Florestal; 03 Pesca e Aquicultura; 10 Fabricação de Produtos Alimentícios; 13 Fabricação de Produtos Têxteis; 14 Confecção de Artigos do Vestuário e Acessórios; 15 Preparação de Couros e Fabricação de Artefatos de Couro, Artigos para Viagem e Calçados; 16 Fabricação de Produtos de Madeira; 20 Fabricação de Produtos Químicos; 21 Fabricação de Produtos 
TABELA 1 - EMPREGO EM ATIVIDADES COM EXPECTATIVA DE ALTA DO ICMS

\begin{tabular}{|c|c|c|c|c|c|c|}
\hline $\begin{array}{c}\text { Divisão } \\
\text { CNAE }\end{array}$ & Descrição & Emprego & $\begin{array}{c}\text { Emprego por } \\
\text { estabelecimento }\end{array}$ & $\begin{array}{l}\text { Empregados } \\
\text { com curso } \\
\text { superior }(\%)\end{array}$ & $\begin{array}{c}\text { Remuneração } \\
\text { média dos } \\
\text { empregados } \\
(\mathbf{R} \$)\end{array}$ & $\begin{array}{c}\text { Remuneração } \\
\text { média agregada } \\
\text { dos empregados } \\
\text { (R\$) }\end{array}$ \\
\hline 11 & FABRICAÇÃO DE BEBIDAS & 295 & 58,03 & 30,23 & 698,71 & \\
\hline 35 & $\begin{array}{l}\text { ELETRICIDADE, GÁS E OUTRAS } \\
\text { UTILIDADES }\end{array}$ & 1561 & 16,51 & 1,71 & 752,05 & 800,64 \\
\hline 61 & TELECOMUNICAÇÕES & 399 & 9,43 & 4,59 & 1066,38 & \\
\hline
\end{tabular}

FONTE: RAIS.

NOTA: Os valores correspondem à média das estatísticas do triênio 2005-2007.

farmacêuticos; 27 Fabricação de Máquinas, Aparelhos e Materiais Elétricos; 28 Fabricação de Máquinas e Equipamentos; 31 Fabricação de Móveis; e 56 Alimentação. A exemplo do caso das Divisões com produtos que devem passar por aumento da alíquota do imposto, não havia dados das Divisões 03 e 56 disponíveis no período desta pesquisa. Como no caso anterior, nosso retrato do emprego nessas atividades é sintetizado na Tabela 2.

As estatísticas dessas tabelas sugerem que a indústria paranaense não deverá sofrer perdas, em termos de emprego e qualificação, com a minirreforma tributária. Embora uma análise adequada deva levar em consideração os efeitos da alteração do imposto em uma dada atividade sobre as cadeias produtivas que a sustentam, depreendemos que as atividades industriais com expectativa de redução do ICMS, cujo emprego soma mais de 350 mil trabalhadores, são grandes o suficiente para absorver os trabalhadores prejudicados pelo aumento do imposto, que somam 2,2 mil empregados.

É importante ter em mente, entretanto, que os resultados dessa inferência podem ser diferentes se os efeitos sobre as cadeias produtivas, mencionados no parágrafo acima, forem considerados: reduções no emprego em atividades que deverão sofrer alta do ICMS virão acompanhadas de diminuições na produção, e conseqüentes reduções na demanda por insumos, que podem vir de atividades beneficiadas por redução na alíquota do ICMS sobre seus produtos e serviços.

Isso significa que, dada a existência de atividades com alta de ICMS, uma redução da alíquota em outra atividade não é condição suficiente para favorecimento do emprego nesta última.

De modo análogo, as atividades que, à primeira vista, deverão passar por uma diminuição da produção decorrente de alta do ICMS, podem assistir a um aumento na 
demanda por insumos por elas produzidos, decorrente do aumento da produção em atividades cuja alíquota do imposto seja reduzida.

TABELA 2 - EMPREGO EM ATIVIDADES COM EXPECTATIVA DE BAIXA DO ICMS

\begin{tabular}{|c|c|c|c|c|c|c|}
\hline $\begin{array}{l}\text { Divisão } \\
\text { CNAE }\end{array}$ & Descrição & Emprego & $\begin{array}{l}\text { Empregados por } \\
\text { estabelecimento }\end{array}$ & \begin{tabular}{|c|} 
Porcentagem \\
de \\
empregados \\
com curso \\
superior \\
\end{tabular} & $\begin{array}{l}\text { Remuneração } \\
\text { média dos } \\
\text { empregados } \\
(\mathbf{R} \$)\end{array}$ & $\begin{array}{c}\text { Remuneração } \\
\text { média agregada } \\
\text { dos empregados } \\
(\mathbf{R} \$)\end{array}$ \\
\hline 01 & $\begin{array}{l}\text { AGRICULTURA, PECUÁRIA E SERVIÇOS } \\
\text { RELACIONADOS }\end{array}$ & 86450 & 3,70 & 2,32 & 575,58 & \\
\hline 02 & PRODUÇÃO FLORESTAL & 12697 & 14,32 & 1,83 & 553,88 & \\
\hline 10 & $\begin{array}{l}\text { FABRICAÇÃO DE PRODUTOS } \\
\text { ALIMENTÍCIOS }\end{array}$ & 399 & 46,07 & 3,10 & 997,66 & \\
\hline 13 & FABRICAÇÃO DE PRODUTOS TÊXTEIS & 385 & 52,60 & 3,73 & 1024,20 & \\
\hline 14 & $\begin{array}{l}\text { CONFECÇÃO DE ARTIGOS DO VESTUÁRIO } \\
\text { E ACESSORIOS } \\
\text { PREPARAÇÃO DE COUROS E FABRICAÇÃO } \\
\text { DE ARTEFATOS DE COURO, ARTIGOS }\end{array}$ & 3880 & 10,39 & 2,46 & 749,26 & \\
\hline 15 & PARA VIAGEM E CALÇADOS & 137484 & 37,93 & 4,47 & 764,88 & 741,91 \\
\hline 16 & FABRICAÇÃO DE PRODUTOS DE MADEIRA & 701 & 46,96 & 32,64 & 3339,78 & \\
\hline 20 & FABRICAÇÃO DE PRODUTOS QUÍMICOS & 46087 & 20,95 & 2,54 & 666,51 & \\
\hline 21 & $\begin{array}{l}\text { FABRICAÇÃO DE PRODUTOS } \\
\text { FARMOQUÍMICOS E FARMACÊUTICOS }\end{array}$ & 17872 & 43,26 & 5,88 & 1161,51 & \\
\hline 27 & $\begin{array}{l}\text { FABRICAÇÃO DE MÁQUINAS, APARELHOS } \\
\text { E MATERIAIS ELÉTRICOS }\end{array}$ & 5790 & 16,19 & 3,87 & 968,57 & \\
\hline 28 & $\begin{array}{l}\text { FABRICAÇÃO DE MÁQUINAS E } \\
\text { EQUIPAMENTOS }\end{array}$ & 28615 & 11,00 & 3,42 & 845,90 & \\
\hline 31 & FABRICAÇÃO DE MÓVEIS & 11624 & 33,89 & 7,80 & 1020,41 & \\
\hline
\end{tabular}

FONTE: RAIS.

NOTA: Os valores correspondem à média das estatísticas do triênio 2005-2007.

\section{CONCLUSÕES}

As atividades produtivas que deverão ser negativamente influenciadas pela minirreforma tributária compreendem cerca de 2,2 mil empregos formais, de acordo com dados do Ministério do Trabalho e Emprego. Segundo a mesma fonte, aproximadamente 352 mil trabalhadores formais poderão ser positivamente influenciados pela diminuição da alíquota do ICMS sobre os bens e serviços que produzem.

Portanto, à luz da teoria econômica, não devemos esperar impactos negativos significativos da minirreforma tributária sobre o emprego industrial formal paranaense. 


\section{REFERÊNCIAS}

RELAÇÃO ANUAL DE INFORMAÇÕES SOCIAIS - RAIS. Brasília: Ministério do Trabalho e Emprego. Disponível em: < http://www.mte.gov.br/>. Acesso em 11/12/2008.

COMISSÃO NACIONAL DE CLASSIFICAÇÃO - IBGE. Disponível em: <http://www.ibge.gov.br/concla>. Acesso em 1/10/2008.

VARIAN, H. R. Microeconomia: conceitos básicos. 7. ed. Rio de Janeiro: Elsevier, 2006. 